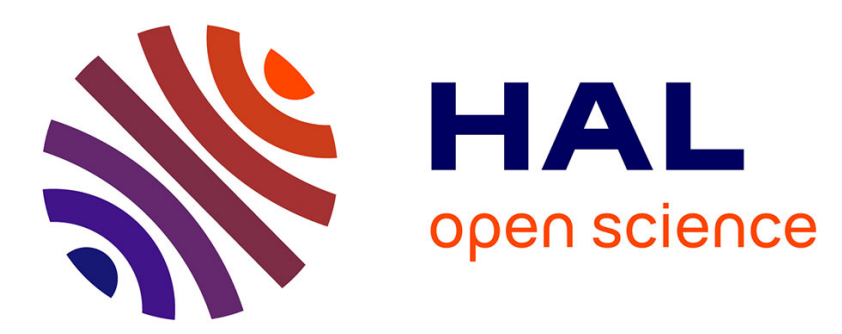

\title{
The rotor pedaling system improves anaerobic but not aerobic cycling performance in professional cyclists
}

\author{
Jose A. Rodríguez-Marroyo, Juan García-López, Karim Chamari, Alfredo \\ Córdova, Olivier Hue, Jose G. Villa
}

\section{- To cite this version:}

Jose A. Rodríguez-Marroyo, Juan García-López, Karim Chamari, Alfredo Córdova, Olivier Hue, et al.. The rotor pedaling system improves anaerobic but not aerobic cycling performance in professional cyclists. European Journal of Applied Physiology, 2009, 106 (1), pp.87-94. 10.1007/s00421-009-0993x . hal-00701238

\section{HAL Id: hal-00701238 \\ https://hal.univ-antilles.fr/hal-00701238}

Submitted on 25 May 2012

HAL is a multi-disciplinary open access archive for the deposit and dissemination of scientific research documents, whether they are published or not. The documents may come from teaching and research institutions in France or abroad, or from public or private research centers.
L'archive ouverte pluridisciplinaire HAL, est destinée au dépôt et à la diffusion de documents scientifiques de niveau recherche, publiés ou non, émanant des établissements d'enseignement et de recherche français ou étrangers, des laboratoires publics ou privés. 


\title{
The rotor pedaling system improves anaerobic but not aerobic cycling performance in professional cyclists
}

\author{
Jose A. Rodríguez-Marroyo · Juan García-López • \\ Karim Chamari · Alfredo Córdova · \\ Olivier Hue $\cdot$ Jose G. Villa
}

Accepted: 12 January 2009/Published online: 31 January 2009

(C) Springer-Verlag 2009

\begin{abstract}
The aims of this study were to evaluate the effects of both noncircular (ROT) and conventional (CON) chainring systems on aerobic and anaerobic cycling performances of professional cyclists, while analyzing the influence of varying the crank angle of maximum crank arm length of ROT. Fifteen professional road cyclists performed both incremental and sub-maximal aerobic tests and the Wingate anaerobic test in the laboratory. There were no statistical differences between CON and ROT in the aerobic tests, even when the best ROT position $(\mathrm{ROT}+)$ was selected. However, in the anaerobic test, maximal $(4.2-9.1 \%)$ and mean $(0.7-4.7 \%)$ power outputs were higher in ROT $(P<0.05)$. These differences were greater when the ROT+ was selected $(11.2$ and $7.0 \%$, respectively). Our findings suggest that ROT is able to improve anaerobic but not aerobic cycling performance in professional cyclists. Nevertheless, it must be adapted to each cyclist to ensure these improvements.
\end{abstract}

J. A. Rodríguez-Marroyo $(\bowtie) \cdot$ J. García-López · J. G. Villa

Department of Physical Education and Sports,

University of León, Campus de Vegazana s/n,

24071 León, Spain

e-mail: j.marroyo@unileon.es

K. Chamari

Research Unit National Center of Medicine and Science in Sport (CNMSS) El Menzah, Tunis, Tunisia

\footnotetext{
A. Córdova

Department of Biochemistry, Molecular Biology

and Physiology, University of Valladolid, Soria, Spain

O. Hue

ACTES Laboratory, UPRES-EA 3596, UFR-STAPS,

University of Antilles-Guyane, Pointe à Pitre, France
}

Keywords Professional cyclist · Noncircular chainring Mechanical efficiency $\cdot$ Maximal power output

\section{Introduction}

Performance in cyclists depends on several factors and recent studies have indicated that biomechanical alterations would also improve performance (Faria et al. 2005b; García-López et al. 2008). During cycling exercise, the force applied to the pedal is not constant along the crank revolution (Faria 1992; Kautz and Hull 1993), this being higher during downstroke (i.e., $0-180^{\circ}, 0^{\circ}$ crank angle is defined as top dead center) than upstroke (i.e., $180-360^{\circ}$ ). Moreover, the effective force is at its minimum when the crank is vertically positioned at both $0^{\circ}$ (top dead center) and $180^{\circ}$ (bottom dead center) (Fregly and Zajac 1996; Neptune and Herzog 2000), consequently, these positions are known as "dead points". For these reasons, a biomechanical strategy to improve cycling performance has been to design noncircular chainrings (Hull et al. 1992) to change these patterns of pedal forces.

The theoretical benefits of these noncircular chainrings are: (1) to eliminate the dead spots (Santalla et al. 2002; Lucía et al. 2004), (2) to increase the crank arm length during the downstroke (Hue et al. 2001; Zamparo et al. 2002) and (3) to slow down the downstroke and accelerate the upstroke (Hull et al. 1992; Martin et al. 2002). Therefore, these chainrings allow highest torques during the crank revolution, mainly during the downstroke. However, none of them allowed varying the crank angle of maximum crank arm length.

When comparing conventional parameters of aerobic cycling performance (e.g., $V \mathrm{O}_{2 \max }$, anaerobic threshold, cycling efficiency, economy), previous studies reported no 
differences between noncircular and circular chainrings (Hull et al. 1992; Cullen et al. 1992; Hue et al. 2001; Ratel et al. 2004; Lucía et al. 2004). Few studies reported advantages (Zamparo et al. 2002; Santalla et al. 2002) or disadvantages (Belen et al. 2007a) when the noncircular chainrings were used. Nevertheless, none of these studies has been carried out with professional road cyclists. Two previous studies used a new noncircular chainring [i.e., the Rotor Pedaling System (ROT)], and showed slight increases in cycling efficiency $(\sim 3 \%)$ when ROT was used by physical education students (Santalla et al. 2002). However, they did not find differences when analyzing trained cyclists (Lucía et al. 2004). Additionally, these ROT models did not allow varying the crank angle of maximum crank arm length.

To the best of our knowledge, only five studies have investigated the effects of noncircular chainrings on anaerobic cycling performance (e.g., all-out tests) compared with conventional chainrings $(\mathrm{CON})$. Martin et al. (2002) found increases in maximal single-leg cycling power when using a noncircular chainring, which supported the previous results obtained by Hue et al. (2001), showing an improvement in an all-out 1-km laboratory test. Hue et al. (2008) have also found improvements during a laboratory force-velocity test. However, in two recent studies no positive improvement was demonstrated using noncircular chainring in an all-out 1-km track cycling test (Belen et al. 2007b; Hue et al. 2007). To date, however, there are no empirical studies assessing the effects of noncircular chainrings on anaerobic cycling performance in professional cyclists.

Therefore, the aim of this study was to assess the effects of ROT compared with CON in professional cyclists performing both aerobic (i.e., maximal incremental and submaximal tests) and anaerobic tests (i.e., Wingate test). In addition, we analyzed the influence of varying the crank angle of maximum crank arm length of ROT (during the downstroke) on both tests.

\section{Methods}

Participants

Fifteen professional road cyclists ( $24 \pm 1$ year, $69.5 \pm$ $1.4 \mathrm{~kg}$ and $1.77 \pm 0.02 \mathrm{~m}$ ) participated in this study. All of them were healthy male competitors of a continental cycling team with several years cycling experience. They had never used ROT before participating in this study. The evaluation protocol was designed according to the Helsinki Conference for research on human beings, and all cyclists signed informed consent before starting the study. The study Protocol was approved by the University of Leon Ethical Committee (Spain).
The Rotor System

The Rotor System (ROT) is a pedal crank system configuration approved by the International Cycling Union. The ROT crank arms are not fixed at $180^{\circ}$ and this eliminates the dead spots that occur with the conventional system (CON) at top-bottom dead centers (Fig. 1a). An extensive explanation of these specific characteristics was reported by Santalla et al. (2002) and Lucía et al. (2004). Another ROT characteristic is that the chainring rotation axis and the crank rotation axis do not coincide (Fig. 1b). The ROT model used in this study (Rotor-RCK, Rotor Bikes Components, Madrid, Spain) allowed varying the crank angle of maximum crank arm length between $116^{\circ}$ (ROT-1), $122^{\circ}$ (ROT-2), $128^{\circ}$ (ROT-3) and $134^{\circ}$ (ROT-4), where $0^{\circ}$ is the crank placed at top dead center. This is an important difference in relation to previous studies on ROT, where only one position of crank angle of maximum crank arm length was tested (Santalla et al. 2002; Lucía et al. 2004). The adjustment of ROT is possible by rotating the chainring around the crank axis (Fig. 1b), and this produces a sinusoidal variation in relative angular velocity of the crank as
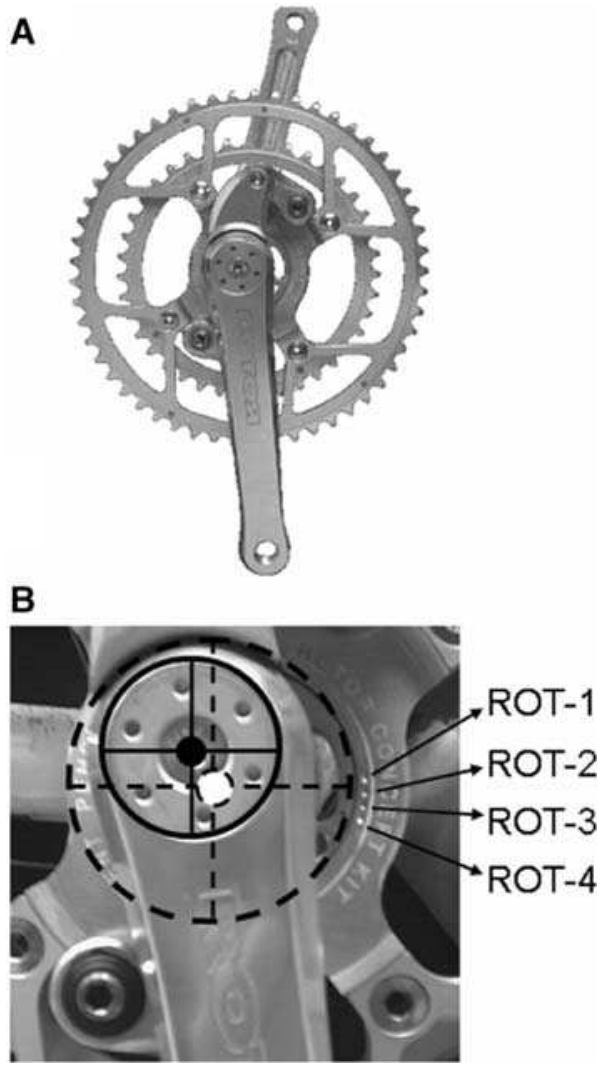

Fig. 1 a The Rotor System used (Rotor-RCK). b Enlarged image of the chainring rotation axis (dotted line) and the crank rotation axis (solid line). The Rotor-RCK allows using four positions of crank angle of maximum crank arm length: $116^{\circ}$ (ROT-1), $122^{\circ}$ (ROT-2), $128^{\circ}$ (ROT-3) and $134^{\circ}$ (ROT-4) 


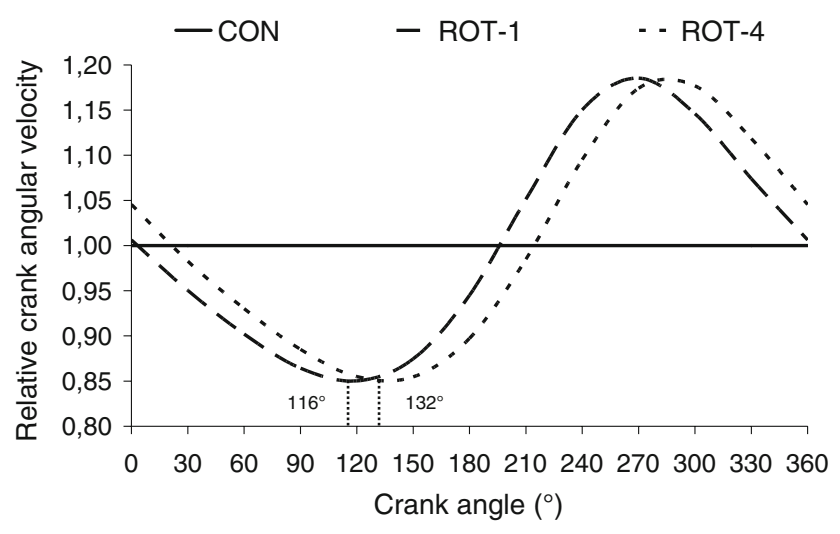

Fig. 2 The theoretical functioning of the Rotor System used in this study (Rotor-RCK). Relative crank angular velocity for a constant chain speed of the CON (solid line), ROT-1 and ROT-4 (dotted lines) within a crank revolution $\left(0-360^{\circ}\right)$

a function of crank angle for a constant chain speed (Fig. 2). Figure 2 expresses a theoretical functioning because the cyclists did not pedal with a constant chain speed, but could be a good approximation to explain how ROT works. Therefore, it could be considered that the relative angular velocity of the crank is lower when the relative crank arm length is higher, and vice versa. By considering that ROT-1 to ROT-4 allows increasing the crank arm length during the downstroke, ROT could slow down the downstroke and accelerate the upstroke.

\section{Experimental design}

At the beginning of the preparation period (December) the cyclists were evaluated in five separate testing sessions (days 1-5) with a recovery period of $48 \mathrm{~h}$ between testing sessions. On days 1 and 2 the cyclists underwent two incremental tests, on day 3 the cyclists carried out a submaximal test, and on days 4 and 5 the cyclists performed various maximal intensity tests (one force-velocity test and five Wingate anaerobic tests). All the testing sessions were performed at the same time of the day (in the morning, between 08:00 and 13:00 h), under similar environmental conditions $\left(20-25^{\circ} \mathrm{C}, 60\right.$ to $65 \%$ relative humidity). Each test was preceded by a 10-min warm-up period at a power output of $100 \mathrm{~W}$ with 5 min separating the end of the warm-up from the testing. The lengths of the crank arms were adapted for all subjects during all tests, and clip-on pedals were used. The incremental and sub-maximal tests were performed on a cyclosimulator (Cateye CS-1000, Cateye Co. Ltd, Osaka, Japan) with the subjects using their own competition cycles, because this could eliminate the problem of the cyclists not being able to configure the cycle to their normal riding posture (Faria et al. 2005a) and has been used in previous studies dealing with noncircular chainrings (Santalla et al. 2002).
The maximal anaerobic tests (i.e., force-velocity and Wingate) were performed on a mechanically braked cycle ergometer (Monark 818E, Monark Exercise AB, Varberg, Sweden), because it has been recognized as a valid and reliable method of anaerobic exercise testing (Micklewright et al. 2006) and has been used in previous research dealing with noncircular chainrings (Hue et al. 2008). The tyre pressure $(8 \mathrm{~atm})$ was the same for all subjects during the tests on the cyclosimulator. All the cyclists performed no more than a light training session the day before the testing sessions.

Incremental test

The cyclists underwent two continuous and progressive maximal oxygen uptake tests to exhaustion, in which they used CON and ROT with the crank angle of maximum crank arm length at $128^{\circ}$ (ROT-3), the order of the tests being randomized. The cyclists chose their preferred gear ratio during the first test; in the second test they were required to use the same gear ratio for each speed. The tests started at $32 \mathrm{~km} \mathrm{~h}^{-1}$ and the bicycle speed was increased by $1 \mathrm{~km} \mathrm{~h}^{-1}$ every $1 \mathrm{~min}$ to exhaustion (Rodríguez-Marroyo et al. 2003), with continuous electrocardiograph (Schiller AG, Baar, Switzerland) and breath-by-breath respiration gas analysis during the whole effort (Medical Graphics System CPX-Plus, Medical Graphics Corporation, St Paul, $\mathrm{MN})$. Heart rate and pedal cadence were monitored telemetrically during the whole duration of the test (Polar Xtrainer Plus, Polar Electro Oy, Kempele, Finland), and the power output was analyzed with a valid and reliable powermeter for pedaling intensities of between 100 and $450 \mathrm{~W}$ (PowerTap, CycleOps, Madison, USA) (Bertucci et al. 2005). The other variables obtained in the test were: oxygen consumption, ventilation, ventilatory equivalents for oxygen and carbon dioxide, and the respiratory exchange ratio. All these variables were averaged for each 10 -s period. $V_{2} \mathrm{O}_{2 \max }$ and maximal power output were recorded as the highest values obtained for the last 10 -s period before exhaustion (Hue et al. 2001). The ventilatory threshold and the respiratory compensation threshold were identified according to Davis's (1985) criteria.

\section{Sub-maximal test}

The cyclists performed one sub-maximal test consisting of five sets of $10 \mathrm{~min}$ on the cyclosimulator with ROT-1, ROT-2, ROT-3, ROT-4 and CON, the order of the sets also being randomized. The power output for the sub-maximal test was set at a value equivalent to $90 \%$ of the power at respiratory compensation threshold during the incremental test with $\mathrm{CON}\left(\sim 75 \% V_{2 \max }\right)$. We selected this power output because: (1) the cyclists did not reach their optimal 
performance in the pre-season period, and it is difficult to sustain the power output at the respiratory compensation threshold for a long period, (2) the respiratory exchange ratio at $90 \%$ of the respiratory compensation threshold was lower than 1.00 in all the cyclists studied. They maintained this power output during 5 sets of 10-min effort period with 15-min recovery in between. The recovery period was used to change and/or to adjust the chainring system. The cyclists were able to drink $100 \mathrm{ml}$ of water during the recovery periods of each test to avoid dehydration. The cyclists selected their preferred gear ratio and cadence during the first set and were required to use the same configuration during the successive sets. Likewise, to eliminate the metabolic cost impact of modifying the cyclists' position during sub-maximal test (Heil et al. 1997), the cyclists used the same posture (i.e., upright sitting position). Heart rate, power output, oxygen consumption, and respiratory exchange ratio were monitored during the entire duration of the test, and were averaged for the last 2 min of each 10-min set. Gross mechanical efficiency was calculated as the ratio of work accomplished (expressed in $\mathrm{kcal} \mathrm{min}^{-1}$ ) to energy expended $\left(\mathrm{kcal} \mathrm{min}^{-1}\right.$ ) (Coyle et al. 1992; Sidossis et al. 1992), using the tables of Westenskow (1988) for the corresponding energy equivalent for each oxygen consumption value based on respiratory exchange ratio. Cycling economy was calculated as the work accomplished per litre of oxygen consumed, and was expressed in $\mathrm{kJ}^{-1}$ (Moseley et al. 2004). The best ROT (ROT+) was obtained for each cyclist from the positions ROT-1, ROT-2, ROT-3 or ROT-4, by selecting the set with higher values of gross mechanical efficiency.

Wingate and force-velocity anaerobic tests

The cyclists performed a force-velocity test and two Wingate anaerobic tests on day 4 , and three Wingate anaerobic tests on day 5, with $\sim 60$ min of recovery in between. The cycle ergometer was adapted to the characteristics of the cyclists' bicycles, and was fixed on the ground to avoid displacement. It was equipped with two 172.5-mm crank arms, a gear ratio of $6.12 \mathrm{~m}$ (flywheel revolutions per pedal crank revolution) and a handlebar and a saddle similar to those used by the cyclists. To record the right crank velocity, four magnetic sensors were placed at $90^{\circ}, 180^{\circ}, 270^{\circ}$ and $360^{\circ}$ crank angle. These sensors were connected to special software (SportSpeed, University of Leon, Spain) validated in a previous study for an accuracy of $500 \mathrm{~Hz}$ (Garcia-Lopez et al. 2005).

The cyclists performed a force-velocity test with CON to obtain the optimal braking force (Vandewalle et al. 1987). It consisted of performing a series of short maximal sprints ( $\sim 6 \mathrm{~s})$ followed by a 5 -min rest. The initial braking force was $20 \mathrm{~N}$, and was increased by $20 \mathrm{~N}$ in each sprint until the subjects were unable to reach a peak crank velocity higher than $100 \mathrm{rpm}$. The optimal braking force was obtained from the relation between force and power by using a third order polynomial function (Arsac et al. 1996). We used this optimal braking force for the five Wingate anaerobic tests, approaching $\sim 0.112 \mathrm{kp}$ per $\mathrm{kg}$ of body mass.

The order of the Wingate anaerobic tests was randomized in the same way as the sub-maximal tests for the ROT and CON devices. These consisted of pedaling at maximal speed for $30 \mathrm{~s}$ against the optimal breaking force obtained in the force-velocity test. The cyclists remained seated on the saddle and they were vigorously encouraged to reach the maximum cadence as soon as possible. In each test, power output was corrected for inertial effects of the flywheel (Lakomy 1986). The variables obtained in the test were: peak power output, mean power output, minimum power output, maximal pedaling rate, time to peak power output, and fatigue rate according to the following equation (Micklewright et al. 2006):

$\mathrm{FR}\left(\mathrm{W} \mathrm{s}^{-1}\right)=\left(P_{\text {peak }}-P_{\text {mean }}\right) \times\left(30-\mathrm{TP}_{\text {peak }}\right)^{-1}$

where FR is the fatigue rate in $\mathrm{W} \mathrm{s}^{-1}, P_{\text {peak }}$ is the peak power output in $\mathrm{W}, P_{\text {mean }}$ is the mean power output in W, and the $\mathrm{TP}_{\text {peak }}$ is the time to the $P_{\text {peak }}$ in s. ROT+ was obtained by selecting the higher values of mean power output of each cyclist with any of the ROT positions.

\section{Statistical analysis}

The results are expressed as mean and the standard error of the mean. Statistical analysis was carried out using SPSS + version 13.0 (Chicago, IL, USA). The Kolmogorov-Smirnov test was applied to ensure a Gaussian distribution of the results. The analyzed variables during the incremental tests (CON and ROT-3) were compared using Student's paired $t$ test. The variables of the sub-maximal and Wingate anaerobic tests (CON, ROT-1, ROT-2, ROT-3 and ROT-4) were compared using an analysis of variance (ANOVA) with repeated measures. Newman-Keuls post hoc analysis was used to establish statistical differences between means. Statistical significance was set at $P<0.05$.

\section{Results}

Incremental test

No statistical differences were found between $\mathrm{CON}$ and ROT-3 in the incremental test (Table 1). 
Table 1 Maximal, respiratory compensation threshold (RCT) and ventilatory threshold $(\mathrm{VT})$ values (mean \pm SEM) during the incremental test

\begin{tabular}{|c|c|c|}
\hline & $\mathrm{CON}$ & ROT-3 \\
\hline \multicolumn{3}{|l|}{ Maximal values } \\
\hline$V \mathrm{O}_{2}\left(\mathrm{ml} \mathrm{kg}^{-1} \min ^{-1}\right)$ & $77.9 \pm 1.7$ & $75.6 \pm 1.6$ \\
\hline HR (bpm) & $191 \pm 2$ & $189 \pm 2$ \\
\hline Power output (W) & $361.3 \pm 9.1$ & $363.1 \pm 9.9$ \\
\hline Power output ( $\mathrm{W} \mathrm{kg}^{-1}$ ) & $5.26 \pm 0.14$ & $5.27 \pm 0.14$ \\
\hline Speed $\left(\mathrm{km} \mathrm{h}^{-1}\right)$ & $52.3 \pm 0.6$ & $52.4 \pm 0.8$ \\
\hline \multicolumn{3}{|l|}{ RCT values } \\
\hline$V \mathrm{O}_{2}\left(\mathrm{ml} \mathrm{kg}^{-1} \mathrm{~min}^{-1}\right)$ & $67.7 \pm 1.7$ & $64.4 \pm 1.9$ \\
\hline HR (bpm) & $178 \pm 3$ & $176 \pm 2$ \\
\hline Power output (W) & $302.9 \pm 8.8$ & $299.6 \pm 10.0$ \\
\hline Power output ( $\mathrm{W} \mathrm{kg}^{-1}$ ) & $4.40 \pm 0.11$ & $4.36 \pm 0.14$ \\
\hline Speed $\left(\mathrm{km} \mathrm{h}^{-1}\right)$ & $48.2 \pm 0.6$ & $47.9 \pm 0.7$ \\
\hline \multicolumn{3}{|l|}{ VT values } \\
\hline$V \mathrm{O}_{2}\left(\mathrm{ml} \mathrm{kg}^{-1} \min ^{-1}\right)$ & $50.9 \pm 1.1$ & $49.6 \pm 0.9$ \\
\hline HR (bpm) & $152 \pm 3$ & $152 \pm 3$ \\
\hline Power output (W) & $223.6 \pm 4.4$ & $219.6 \pm 3.9$ \\
\hline Power output ( $\mathrm{W} \mathrm{kg}^{-1}$ ) & $3.26 \pm 0.08$ & $3.19 \pm 0.05$ \\
\hline Speed $\left(\mathrm{km} \mathrm{h}^{-1}\right)$ & $41.2 \pm 0.5$ & $40.6 \pm 0.4$ \\
\hline
\end{tabular}

CON conventional pedaling system, ROT-3 rotor pedaling systems

Sub-maximal test

No statistical differences were found between CON and ROT in the sub-maximal test (Table 2), independently of the crank angle of maximum crank arm length with ROT (i.e., ROT-1, ROT-2, ROT-3 or ROT-4). Furthermore, we did not find any difference when ROT + and CON were compared.

\section{Wingate anaerobic test}

Both peak (4.2-9.1\%) and mean (0.7-4.7\%) power outputs with ROT were always greater than CON (Table 3). However, these differences were only statistically significant when comparing the peak power output in ROT-3 and ROT-4, and the mean power output in ROT-4. The maximal pedaling rate was greater with ROT-4 than $\mathrm{CON}(P<0.05)$. Both peak $(11.2 \%)$ and mean $(7.0 \%)$ power outputs were higher with ROT+ than $\mathrm{CON}(P<0.05)$, whereas the time to peak power output was lower with ROT+ than CON $(P<0.05)$, and no statistical differences were found for the fatigue rate. Power output was higher with ROT + than $\mathrm{CON}$ $(P<0.05)$ during the first $25 \mathrm{~s}$ (Fig. 3$)$.

\section{Discussion}

The main finding of our study was that Rotor System (ROT) is able to improve the anaerobic performance during the Wingate anaerobic test, but seems not to be able to improve either aerobic power (measured via the $V \mathrm{O}_{2 \max }$ ) or aerobic cycling efficiency (measured via the gross mechanical efficiency and the cycling economy) in professional cyclists when compared to CON.

We hypothesized that ROT's mechanical characteristics (Figs. 1,2) possibly improved the performance during the Wingate anaerobic test (Table 3; Fig. 3), because ROT allowed varying the length of a crank arm of $175 \mathrm{~mm}$ between $205.8 \mathrm{~mm}$ (crank angle of maximum crank arm length) and $147.6 \mathrm{~mm}$ (crank angle of minimum crank arm length). This variation of crank arm length probably allowed a higher force/power production during the downstroke and a lower negative momentum (negative force $\times$ distance) during the upstroke (Neptune and Herzog 2000; Sanderson et al. 2000). Some studies used this same strategy and also observed improvements during several anaerobic tests (Hue et al. 2001). For example, Hue and colleagues varied $25 \mathrm{~mm}$ the crank arm length and showed improvements between $\sim 7 \%$ (Hue et al. 2001) and $\sim 10 \%$ (Hue et al. 2008). Martin et al. (2002) varied the crank arm length by $20 \mathrm{~mm}$ and showed greater power (between 4-8\%). These improvements were similar to those obtained in the present study with ROT (4-9\%, Table 3). Nevertheless, another study (Belen et al. 2007b) did not show statistical differences between circular and noncircular chainrings during an anaerobic test, possibly because they used an inverse strategy, and the crank arm

Table 2 Parameters evaluated (mean \pm SEM) during sub-maximal test with conventional $(\mathrm{CON})$ and Rotor (ROT-1, ROT-2, ROT-3 and ROT-4) pedaling systems

\begin{tabular}{|c|c|c|c|c|c|c|}
\hline & $\mathrm{CON}$ & ROT-1 & ROT-2 & ROT-3 & ROT-4 & ROT + \\
\hline GE $(\%)$ & $20.7 \pm 0.8$ & $20.5 \pm 0.8$ & $20.5 \pm 0.9$ & $20.9 \pm 1.0$ & $21.1 \pm 0.9$ & $21.6 \pm 1.0$ \\
\hline $\mathrm{CE}\left(\mathrm{kJ}^{-1}\right)$ & $4.3 \pm 0.2$ & $4.2 \pm 0.2$ & $4.2 \pm 0.2$ & $4.3 \pm 0.2$ & $4.3 \pm 0.2$ & $4.4 \pm 0.2$ \\
\hline$V \mathrm{O}_{2}\left(\mathrm{ml} \mathrm{kg}^{-1} \min ^{-1}\right)$ & $55.8 \pm 1.8$ & $56.3 \pm 1.8$ & $56.3 \pm 1.9$ & $55.4 \pm 2.0$ & $55.0 \pm 1.8$ & $53.8 \pm 1.9$ \\
\hline$\% V \mathrm{O}_{2 \max }$ & $76.2 \pm 2.0$ & $76.9 \pm 1.8$ & $76.9 \pm 1.9$ & $75.7 \pm 2.0$ & $75.2 \pm 2.1$ & $73.6 \pm 2.0$ \\
\hline HR (beats $\min ^{-1}$ ) & $153 \pm 2$ & $154 \pm 2$ & $153 \pm 2$ & $154 \pm 2$ & $153 \pm 2$ & $151 \pm 2$ \\
\hline
\end{tabular}

$G E$ gross mechanical efficiency, $C E$ cycling economy, $R O T+$ the best ROT position 
Table 3 Parameters evaluated (mean \pm SEM) during Wingate anaerobic tests with conventional (CON) and Rotor (ROT-1, ROT-2, ROT-3 and ROT-4) pedaling systems

\begin{tabular}{|c|c|c|c|c|c|c|}
\hline & $\mathrm{CON}$ & ROT-1 & ROT-2 & ROT-3 & ROT-4 & ROT+ \\
\hline$P_{\text {peak }}(\mathrm{W})$ & $977.9 \pm 31.9$ & $1021.6 \pm 28.5$ & $1018.6 \pm 32.7$ & $1023.7 \pm 34.6^{*}$ & $1067.3 \pm 31.9^{*}$ & $1087.3 \pm 30.6^{*}$ \\
\hline$P_{\text {peak }}\left(\mathrm{W} \mathrm{kg}^{-1}\right)$ & $14.09 \pm 0.42$ & $14.71 \pm 0.41$ & $14.68 \pm 0.40$ & $14.89 \pm 0.43^{*}$ & $15.38 \pm 0.38^{*}$ & $15.68 \pm 0.39 *$ \\
\hline $\mathrm{RPM}_{\max }(\mathrm{rpm})$ & $124 \pm 3$ & $123 \pm 3$ & $124 \pm 4$ & $129 \pm 3^{*}$ & $129 \pm 3^{*}$ & $131 \pm 3^{*}$ \\
\hline $\mathrm{TP}_{\text {peak }}(\mathrm{s})$ & $5.9 \pm 0.4$ & $5.5 \pm 0.3$ & $5.2 \pm 0.2$ & $5.3 \pm 0.3$ & $5.6 \pm 0.2$ & $4.7 \pm 0.1^{*}$ \\
\hline$P_{\text {mean }}(\mathrm{W})$ & $676.1 \pm 19.3$ & $692.8 \pm 18.9$ & $681.0 \pm 18.0$ & $693.2 \pm 19.4$ & $707.9 \pm 19.8^{*}$ & $723.4 \pm 18.3^{*}$ \\
\hline$P_{\text {mean }}\left(\mathrm{W} \mathrm{kg}^{-1}\right)$ & $9.73 \pm 0.21$ & $10.05 \pm 0.22$ & $9.83 \pm 0.20$ & $10.07 \pm 0.22$ & $10.21 \pm 0.24^{*}$ & $10.43 \pm 0.21^{*}$ \\
\hline $\mathrm{FR}\left(\mathrm{W} \mathrm{s}^{-1}\right)$ & $19.6 \pm 1.0$ & $20.6 \pm 1.0$ & $22.0 \pm 1.2^{*}$ & $20.2 \pm 1.4$ & $22.4 \pm 0.8^{*}$ & $18.8 \pm 1.0$ \\
\hline $\mathrm{FR}\left(\mathrm{W} \mathrm{s} \mathrm{s}^{-1} \mathrm{~kg}^{-1}\right)$ & $0.28 \pm 0.01$ & $0.30 \pm 0.02$ & $0.32 \pm 0.02 *$ & $0.29 \pm 0.02$ & $0.32 \pm 0.01 *$ & $0.27 \pm 0.01$ \\
\hline
\end{tabular}

$P_{\text {peak }}$ maximal power output, $R P M_{\max }$ maximal pedaling rate, $T P_{\text {peak }}$ time for power output to peak, $P_{\text {mean }}$ mean power output, $F R$ fatigue rate, $R O T+$ the best ROT position

* Significant difference with CON $(P<0.05)$

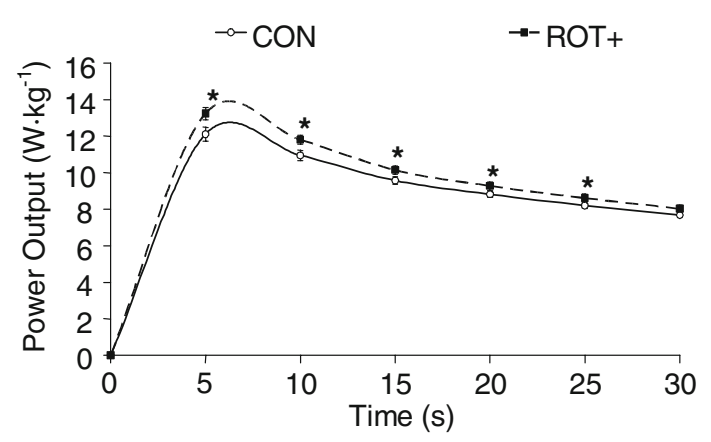

Fig. 3 Comparison of the time course of power output between conventional $(\mathrm{CON})$ pedaling system and the best Rotor $(\mathrm{ROT}+)$ during Wingate anaerobic test. * Significant differences $(P<0.05)$

length decreased $10 \mathrm{~mm}$ at $90^{\circ}$ and increased $10 \mathrm{~mm}$ at $270^{\circ}$. This could produce an opposite effect to the one described in the previous paragraph, not allowing an improvement in the anaerobic cycling performance.

During the Wingate anaerobic test the pedal cadence (123-129 rpm, Table 3) was in an optimum range (110$140 \mathrm{rpm}$ ) to obtain the maximal power output (Samozino et al. 2007; Martin et al. 2007). Sixty-eight percent of the cyclists obtained ROT + by using ROT-4, and the 25, 5 and $2 \%$ of them by using ROT-3, ROT-2 and ROT-1, respectively. Consequently, mean and peak power outputs were higher in ROT-3 and ROT-4 than in CON (Table 3). According to these results, we can hypothesize that noncircular chainrings need to be adapted to each cyclist to improve anaerobic performance. This could be due to: (1) by considering the theoretical functioning of ROT (Fig. 2), unlike ROT-1 and ROT-2, ROT-3 and ROT-4 could shorten the time the cranks are at the top dead center $\left(0^{\circ}\right)$, because the relative crank angular velocity could be higher. However, future studies with ROT should evaluate the adjustment between its theoretical and practical functioning (crank angular kinematics). (2) Also, ROT-3 and ROT-4 clearly introduce the crank angle of maximum crank arm length after $120^{\circ}\left(128^{\circ}\right.$ and $134^{\circ}$, respectively). This could maximize the contribution of the non-muscular component of the pedal reaction force, it being higher than the muscular component at high cadences (Neptune and Herzog 1999), and increasing its maximum magnitude to crank angles higher than $120^{\circ}$ at $105-120 \mathrm{rpm}$ (Kautz and Hull 1993). Nevertheless, future studies with ROT should confirm this last hypothesis by performing a kinetic analysis. It is important to note that the ROT used in this study is the only model of noncircular chainring that allows varying the crank angle of maximum crank arm length, and setting it above $120^{\circ}$.

Some studies consider that performing the anaerobic test in the laboratory (e.g., Wingate anaerobic test) or in the field (e.g., 1-km all-out in velodrome) could affect the results, because in the laboratory the cyclists do not usually use their bicycles (Hull et al. 1992), the ergometers do not usually oscillate from side to side (Bertucci et al. 2005), and aerodynamic drag does not exist (Martin et al. 2007). Nevertheless, Gardner et al. (2007) did not find differences between velodrome and laboratory results of seven elite track cyclists, and speculated about the possible influence of skill performance to produce similar power during laboratory and field trials. This hypothesis deserves further study, and future field studies should examine whether the Rotor System could improve performance in short track cycling competitions (e.g., 200-m sprint). We obtained a lower maximal power output with CON $\left(\sim 14 \mathrm{~W} \mathrm{~kg}^{-1}\right.$, Table 3) than the cyclists studied by Calbet et al. (2003) (between 17-21 $\mathrm{W} \mathrm{kg}^{-1}$ ) who used the same ergometer as in the present study, possibly because our subjects were race cyclists and not track cyclists.

We did not find statistical differences between ROT and CON during the incremental (Table 1) and sub-maximal 
tests (Table 2). These results coincided with the majority of previous studies that compared circular and noncircular chainrings during incremental tests (Henderson et al. 1977; Santalla et al. 2002; Lucía et al. 2004; Ratel et al. 2004) and sub-maximal tests (Cullen et al. 1992; Hull et al. 1992; Ratel et al. 2004; Lucía et al. 2004). Contrary to these findings, other previous studies with ROT seemed to exhibit higher delta mechanical efficiency at 60-90\% $V \mathrm{O}_{2 \max }$ during an incremental test (Santalla et al. 2002), but follow-up testing failed to confirm these results (Lucía et al. 2004). Zamparo et al. (2002) obtained a small improvement $(1.3-1.8 \%)$ with a noncircular chainring at 250-300 W, but they evaluated seven non-professional road cyclists who pedalled at $60 \mathrm{rpm}$, and only four and the two cyclists were able to pedal aerobically (respiratory exchange ratio lower than 1.00) up to 250 and $300 \mathrm{~W}$, respectively. Only one study showed lower performance with a peculiar noncircular chainring (Belen et al. 2007a), which decreased and increased the crank arm length by $25 \mathrm{~mm}$ at $90^{\circ}$ and $270^{\circ}$, respectively; they also evaluated physical education students who had little experience of cycling, and all of them used the same bicycle. According to our results and those of the majority of previous studies, we can hypothesize that noncircular chainrings do not improve aerobic performance during prolonged pedaling exercise. This could be due to: (1) different theoretical and practical functioning of noncircular chainrings (crank angular kinematics), because most of the optimization analyses of cycling performance were aimed at maximizing short-term power production and not cycling efficiency (Hull et al. 1992). Therefore, future studies with ROT should evaluate the adjustment between its theoretical (Fig. 2) and practical functioning; (2) the inclusion of additional parts which imply supplementary weight and friction (Belen et al. 2007a), because Rotor-RCK weighs $\sim 350 \mathrm{~g}$ more than $\mathrm{CON}$ and has a shorter stopping time after rotating; (3) the cycling experience (Lucía et al. 2004), because the well-trained cyclists could not use the theoretical biomechanical advantage brought about by ROT.

The cyclists who participated in the present study had not used ROT previously, and this could condition our results. Nevertheless, Lucía et al. (2004) compared the cycling mechanical efficiency of five cyclists who used ROT for 8-9 months and five cyclists who had not used ROT previously and there were no significant differences between these two groups. Furthermore, a study by Neptune and Herzog (2000) showed that the adaptation to the subjects' muscle coordination occurred within the first 10-20 cycles after switching to the noncircular chainring. However, it could be that the positive effects of noncircular chainrings during aerobic cycling exercise could be effective in subjects training with, and only with, these chainrings for long time (i.e., several years). Future longitudinal studies with more subjects and more time of training than Lucía et al. (2004) are necessary to elucidate this question.

In conclusion, ROT is able to improve anaerobic performance during the Wingate test but not aerobic power (measured during an incremental test) or aerobic response (elicited during a sub-maximal test) in professional road cyclists when compared with CON. The improvement in the Wingate anaerobic test was in a range of 4-9\%, similar to previous studies that used noncircular chainrings during various anaerobic tests. This could be due to: the elimination of dead points, variation in crank angular velocity, the individualization of the crank angle of maximum crank arm length, which could involve a short time with the cranks at top dead center, and a higher contribution of the nonmuscular component during the downstroke. We suggest that the crank angle of maximum crank arm length must be adapted to each cyclist to improve anaerobic performance. Future studies should test if this ROT model (Rotor-RCK) improves anaerobic performance during a short field test. ROT did not improve aerobic power (incremental test) or cycling economy and gross mechanical efficiency (submaximal test), which could be due to: its higher weight ( $\sim 350 \mathrm{~g}$ ) and friction when compared with CON, and the influence of cycling experience, because we evaluated professional cyclists. Future studies with ROT should evaluate the adjustment between its theoretical and practical functioning (crank angular kinematics), its influence on the pattern of force application (pedal reaction forces), and also its longitudinal effects (several years of training) on the aerobic cycling performance.

Acknowledgments The authors would like to thank the professional road cyclists who participated in this study for their collaboration. This work has been supported by the Consejería de Educación y Cultura de la Junta de Castilla y León (Spain) and the Consejo Superior de Deportes. Ministerio de Educación, Cultura y Deporte, Spain (Grant 12/UPB10/07).

\section{References}

Arsac LM, Belli A, Lacour JR (1996) Muscle function during brief maximal exercise: accurate measurements on a friction-loaded cycle ergometer. Eur J Appl Physiol 74:100-106. doi:10.1007/ BF00376501

Belen L, Habrard M, Micallef JP, Le Gallais D (2007a) The performance and efficiency of cycling with a carbon fiber eccentric chainring during incremental exercise. J Sports Med Phys Fitness 47:40-45

Belen L, Habrard M, Micallef JP, Perrey S, Le Gallais D (2007b) Cycling performance and mechanical variables using a new prototype chainring. Eur J Appl Physiol 101:721-726. doi:10. 1007/s00421-007-0547-z

Bertucci W, Duc S, Villerius V, Pernin JN, Grappe F (2005) Validity and reliability of the PowerTap mobile cycling powermeter 
when compared with the SRM device. Int J Sports Med 26:868873. doi:10.1055/s-2005-837463

Calbet JA, de Paz JA, Garatachea N, Cabeza de Vaca S, Chavarren J (2003) Anaerobic energy provision does not limit Wingate exercise performance in endurance-trained cyclists. J Appl Physiol 94:668-676

Coyle EF, Sidossis LS, Horowitz JF, Beltz JD (1992) Cycling efficiency is related to the percentage of type I muscle fibers. Med Sci Sports Exerc 24:782-788

Cullen LK, Andrew K, Lair KR, Widger MJ, Timson BF (1992) Efficiency of trained cyclists using circular and noncircular chainrings. Int J Sports Med 13:264-269. doi:10.1055/s-20071021264

Davis JA (1985) Anaerobic threshold: a review of the concept and directions for future research. Med Sci Sports Exerc 17:6-18

Faria IE (1992) Energy expenditure, aerodynamics and medical problems in cycling. An update. Sports Med 14:43-63. doi: 10.2165/00007256-199214010-00004

Faria E, Parker DL, Faria IE (2005a) The science of cycling. Factor affecting performance, part 1. Sports Med 35:285-312. doi: 10.2165/00007256-200535040-00002

Faria E, Parker DL, Faria IE (2005b) The science of cycling. Factor affecting performance, part 2. Sports Med 35:313-337. doi: 10.2165/00007256-200535040-00003

Fregly BJ, Zajac FE (1996) A state-space analysis of mechanical energy generation, absorption, and transfer during pedalling. J Biomech 29:81-90. doi:10.1016/0021-9290(95)00011-9

Garcia-Lopez J, Peleteiro J, Rodriguez-Marroyo JA, Morante JC, Herrero JA, Villa JG (2005) The validation of a new method that measures contact and flight times during vertical jump. Int $\mathbf{J}$ Sports Med 26:294-302. doi:10.1055/s-2004-820962

García-López J, Rodríguez-Marroyo JA, Juneau CE, Peleteiro J, Martínez AC, Villa JG (2008) Reference values and improvement of aerodynamic drag in professional cyclists. J Sports Sci 26:277-286. doi:10.1080/02640410701501697

Gardner AS, Martin JC, Martin DT, Barras M, Jenkins DG (2007) Maximal torque- and power-pedalling rate relationships for elite sprint cyclists in laboratory and field tests. Eur J Appl Physiol 101:287-292. doi:10.1007/s00421-007-0498-4

Heil DP, Derrick TR, Whittlesey S (1997) The relationship between preferred and optimal positioning during submaximal cycle ergometry. Eur J Appl Physiol 75:160-165. doi:10.1007/ s004210050141

Henderson SC, Ellis RW, Klimovitch G, Brooks GA (1977) The effects of circular and elliptical chainwheels on steady-rate cycle ergometer work efficiency. Med Sci Sports Exerc 9:202-207

Hue O, Galy O, Hertogh C, Casties JF, Prefaut C (2001) Enhancing cycling performance using an eccentric chainring. Med Sci Sports Exerc 33:1006-1010. doi:10.1097/00005768-200106000-00021

Hue O, Chamari K, Damiani M, Blonc S, Hertogh C (2007) The use of an eccentric chainring during an outdoor 1-km all-out cycling test. J Sci Med Sport 10:180-186. doi:10.1016/j.jsams.2006.05.028

Hue O, Racinais S, Chamari K, Damiani M, Hertogh C, Blonc S (2008) Does an eccentric chainring improve conventional parameters of neuromuscular power. J Sci Med Sport 11:264 270. doi:10.1016/j.jsams.2007.06.004

Hull ML, Williams M, Williams K, Kautz S (1992) Physiological response to cycling with both circular and noncircular chainrings. Med Sci Sports Exerc 24:1114-1122. doi:10.1249/ 00005768-199210000-00008

Kautz SA, Hull ML (1993) A theoretical basis for interpreting the force applied to the pedal in cycling. J Biomech 26:155-165. doi:10.1016/0021-9290(93)90046-H
Lakomy HK (1986) Measurement of work and power output using friction-loaded cycle ergometers. Ergonomics 29:509-517. doi: $10.1080 / 00140138608968287$

Lucía A, Balmer J, Davison RC, Pérez M, Santalla A, Smith PM (2004) Effects of the rotor pedalling system on the performance of trained cyclists during incremental and constant-load cycleergometer test. Int J Sports Med 25:479-485. doi:10.1055/ s-2004-820941

Martin JC, Lamb SM, Brown NA (2002) Pedal trajectory alters maximal single-leg cycling power. Med Sci Sports Exerc 34:1332-1336. doi:10.1097/00005768-200208000-00015

Martin JC, Davidson CJ, Pardyjak ER (2007) Understanding sprintcycling performance: the integration of muscle power, resistance, and modeling. Int J Sports Physiol Perform 2:15-21

Micklewright D, Alkhatib A, Beneke R (2006) Mechanically versus electro-magnetically braked cycle ergometer: performance and energy cost of the Wingate anaerobic test. Eur J Appl Physiol 96:748-751. doi:10.1007/s00421-006-0145-5

Moseley L, Achten J, Martin JC, Jeukendrup AE (2004) No differences in cycling efficiency between world-class and recreational cyclists. Int J Sports Med 25:374-379. doi:10.1055/ s-2004-815848

Neptune RR, Herzog W (1999) The association between negative muscle work and pedaling rate. J Biomech 32:1021-1026. doi: 10.1016/S0021-9290(99)00100-1

Neptune RR, Herzog W (2000) Adaptation of muscle coordination to altered task mechanics during steady-state cycling. J Biomech 33:165-172. doi:10.1016/S0021-9290(99)00149-9

Ratel S, Duché P, Hautier CA, Williams CA, Bedu M (2004) Physiological responses during cycling with noncircular "Harmonic" and circular chainrings. Eur J Appl Physiol 91: 100-104. doi:10.1007/s00421-003-0937-9

Rodríguez-Marroyo JA, García-López J, Avila C, Jiménez F, Cordova A, Villa JG (2003) Intensity of exercise according to topography in professional cyclists. Med Sci Sports Exerc 35:1209-1215. doi:10.1249/01.MSS.0000074562.64053.4F

Samozino P, Horvais N, Hintzy F (2007) Why does power output decrease at high pedaling rates during sprint cycling? Med Sci Sports Exerc 39:680-687. doi:10.1249/MSS.0b013e3180315246

Sanderson DJ, Henning EM, Black AH (2000) The influence of cadence and power output on force application and in shoe pressure distribution during cycling by competitive and recreational cyclists. J Sports Sci 18:173-181. doi:10.1080/02640 4100365072

Santalla A, Manzano JM, Pérez M, Lucía A (2002) A new pedaling design: the rotor-effects on cycling performance. Med Sci Sports Exerc 34:1854-1858. doi:10.1097/00005768-200211000-00024

Sidossis LS, Horowitz JF, Coyle EF (1992) Load and velocity of contraction influence gross and delta mechanical efficiency. Int $\mathbf{J}$ Sports Med 13:407-411. doi:10.1055/s-2007-1021289

Vandewalle H, Peres G, Heller J, Panel J, Monod H (1987) Forcevelocity relationship and maximal power on a cycle ergometer. Correlation with the height of a vertical jump. Eur J Appl Physiol 56:650-656. doi:10.1007/BF00424805

Westenskow DR (1988) Calculation of metabolic expenditure and substrate utilization from gas exchange measurements. J Parenter Enter Nutr 12:20-24. doi:10.1177/014860718801200120

Zamparo P, Minetti AE, Di Prampero PE (2002) Mechanical efficiency of cycling with a new developed pedal-crank. J Biomech 35:1387-1398. doi:10.1016/S0021-9290(02)00071-4 